\title{
The Similarity between Species Composition of Vegetation and Soil Seed Bank of Grasslands in Inner Mongolia, China: Implications for the Asymmetric Response to Precipitation
}

\author{
Yanyan Lv ${ }^{1,2}$, Menghong Shen ${ }^{2}\left(\mathbb{D}\right.$, Baoping Meng ${ }^{1,2, *} \mathbb{C}$, Huifang Zhang ${ }^{1,2}$, Yi Sun ${ }^{1,2}$, Jianguo Zhang ${ }^{1,2}$, \\ Li Chang ${ }^{3}$, Jingrong $\mathrm{Li}^{4}$ and Shuhua $\mathrm{Yi}^{1,2, *(\mathbb{D})}$ \\ 1 Institute of Fragile Eco-Environment, Nantong University, Nantong 226007, China; lvyy18@ntu.edu.cn (Y.L.); \\ zhf10658@ntu.edu.cn (H.Z.); sunyi@ntu.edu.cn (Y.S.); sezjg@ntu.edu.cn (J.Z.) \\ 2 School of Geographic Science, Nantong University, Nantong 226007, China; 1822011031@stmail.ntu.edu.cn \\ 3 College of Geography and Environmental Engineering, Lanzhou City University, Lanzhou 730070, China; \\ changli@lzcu.edu.cn \\ 4 Institute of Water Resources for Pastoral Area, Ministry of Water Resources, Hohhot 010020, China; \\ lijinrong918@126.com \\ * Correspondence: mengbp09@lzu.edu.cn (B.M.); yis@ntu.edu.cn (S.Y.)
}

check for updates

Citation: Lv, Y.; Shen, M.; Meng, B.; Zhang, H.; Sun, Y.; Zhang, J.;

Chang, L.; Li, J.; Yi, S. The Similarity between Species Composition of Vegetation and Soil Seed Bank of Grasslands in Inner Mongolia, China: Implications for the Asymmetric Response to Precipitation. Plants 2021, 10, 1890. https://doi.org/10.3390/ plants10091890

\section{Academic Editors:}

Daniel Sánchez-Mata and Jess K. Zimmerman

Received: 20 July 2021

Accepted: 9 September 2021

Published: 13 September 2021

Publisher's Note: MDPI stays neutral with regard to jurisdictional claims in published maps and institutional affiliations.

Copyright: (c) 2021 by the authors. Licensee MDPI, Basel, Switzerland. This article is an open access article distributed under the terms and conditions of the Creative Commons Attribution (CC BY) license (https:/ / creativecommons.org/licenses/by/ $4.0 /)$.
Abstract: The asymmetric response of productivity to precipitation was recently proposed as an early warning signal for the shifts in temperate grassland function in China. It was hypothesized that the asymmetry was influenced by the increased growth of the newly emerged seedlings from the soil seed bank. Therefore, the seed density in the soil seed bank and the similarity between species composition of the vegetation and the soil seed bank should be maximized where asymmetry was maximized. However, this knowledge was still limited and unconfirmed. In this study, the desert steppe, typical steppe and the transition zone between them (with the highest asymmetry) were selected for studying the similarity index in both 2018 (dry year) and 2019 (wet year). Plant species composition was monitored in situ using an unmanned aerial vehicle. Soil seed bank samples were collected, and the seed bank density and species composition were then examined and identified in the laboratory. Results showed that: (1) The variation in vegetation species richness between the two years was the highest $(41 \%)$ in the transition zone $(p<0.05)$, while it was only $7 \%$ and $13 \%$ for the desert steppe and typical steppe, respectively. The presence of herbaceous species mainly caused the differences in variation among three grassland types. (2) Seed density was the highest in the transition zone (114 seeds $/ \mathrm{m}^{2}$ and 68 seeds $/ \mathrm{m}^{2}$ in the transient and persistent soil seed bank, respectively) $(p<0.05)$. Additionally, herbaceous species were the main components of the soil seed bank. (3) The similarity index was the highest in the transition zone $(p<0.05)$, with $38 \% / 44 \%$ and 33\%/44\% for the transient/persistent soil seed bank in 2018 and 2019, respectively. Our study demonstrated that variation in vegetation species composition was very similar to the composition of the seeds accumulated in the soil seed bank. These results warrant further investigation for the mechanism of asymmetric response of productivity to precipitation.

Keywords: asymmetry; vegetation; seed density; similarity index; unmanned aerial vehicle

\section{Introduction}

Grasslands play a crucial role in both carbon and water cycles. The semi-arid and arid grasslands are experiencing frequent and intense droughts [1,2], which inevitably cause changes in the function, structure, and composition of grassland ecosystems [3-5]. Sometimes, the changes are catastrophic and irreversible, particularly in the North American Great Plains [6]. Therefore, understanding the early warning signals has great importance for grassland ecosystem services and human well-being.

The early warning signals have received much attention in recent years $[7,8]$. The relationship between above-ground net primary production (ANPP) and precipitation was 
an essential predictive signal of grassland functions [9]. The nonlinear response of ANPP to precipitation (asymmetry) has either been studied with models [9,10] or tested in desert [11] and switchgrass [12]. Recently, Hu et al. (2018) found that the asymmetry was maximized at the transition zone between the desert steppe and typical steppe in Inner Mongolia, China [13], and it was proposed to be such a warning signal for the temperate grassland ecosystems [13]. These results suggested that in the extremely dry years the zone was more similar to the desert steppe, and in extremely wet years it was more similar to the typical steppe. Plant density variation [11] and drought tolerance of resident plants [14] have been posited to be the determining factors for the asymmetry. Studies also hypothesized that seedlings that emerged from the soil seed bank beneath bare ground strongly influenced the asymmetry $[13,15,16]$. However, empirical study of this is lacking.

The soil seed bank is defined as the viable seeds that exist on the soil surface or are buried in soil [17], which represents the memories of the last plant community and the development of a future plant community in the surrounding area [18]. It is generally considered that the soil seed bank is the seed resource of native vascular plants, and would supply most seedlings for vegetation regeneration $[19,20]$. It is well-known that the amount of newly emerged seedlings is not only related to soil seed bank density [21,22], but also seed germination status and species composition. The latter can be quantified as a similarity index between soil seed bank species and vegetation species composition $[19,23]$. There have been numerous studies that have investigated the density of soil seed banks or their similarity index in Inner Mongolia [24-29]. Seeds accumulated in the soil seed bank would rapidly complete their life cycle even with only a few tens of millimeters of precipitation in the transition zone [20]. However, previous studies were conducted with varying numbers and sizes of samples and collection times. Furthermore, few have studied different grassland types within different regions, which prevented our further understanding of the potential role of soil seed banks on the asymmetry.

The main objective of this study is to provide evidence of the potential contribution to asymmetry with the measurement of the soil seed bank density and similarity index for three representative grassland types (desert steppe, typical steppe and the transition zone) across Inner Mongolia, China. Since the asymmetry was maximized at the transition zone, we hypothesize that the soil seed bank density and/or the similarity index are also maximized at this zone.

\section{Methods}

\subsection{Study Area}

This study was conducted in the desert steppe, typical steppe, and the transition zone across Inner Mongolia, China (Figure 1). The study area is distributed along a mean annual precipitation gradient ranging from about $100-300 \mathrm{~mm}$, with approximately $65-70 \%$ of the total annual precipitation occurring in the peak growing season from June to August. The mean annual temperature ranges from $3-9{ }^{\circ} \mathrm{C}$. Soils shift from calcic brown/desert steppe soils to chernozems and chestnut soils. Redundancy of plant functional types determines the stability of the grassland in Inner Mongolia [30]. Desert steppe is sensitive to species loss because of its limited functional redundancy, while typical steppe is less sensitive because its dominant grass genus, Stipa, is resistant to herbivory and drought [31]. Desert steppe is characterized by short $(10-25 \mathrm{~cm})$ xerophytic species (mainly short shrubs and semi-shrubs) with sparse cover (15-45\%) and low species richness (5-10 species in $1 \mathrm{~m}^{2}$ ). The predominate plant species are Reaumuria songarica, Potaninia mongolica, Sarcozygium xanthoxylon, Nitraria tangutorum and Kalidium foliatum. The typical steppe is more productive than desert steppe and has continuous vegetation cover. Relatively xerophytic tufted perennial grasses mainly dominate the vegetation. The plant communities have a height of 14-35 cm, 30-50\% cover and moderate levels of diversity (12-15 species in $1 \mathrm{~m}^{2}$ ) [32]. The predominating plant species are Stipa capillata, Leymus chinensis, Artemisia capillaris, Artemisia scoparia and Chenopodium glaucum. The vegetation of the transition zone consists of both shrubs and herbaceous species [33]. The species richness lies between the 
desert steppe and typical steppe. According to Hu et al. (2018) [13], the asymmetry was the highest in the transition zone, while lower in the desert steppe and typical steppe. This zone is more similar to the desert steppe in the extremely dry years, and it is more similar to the typical steppe in the extremely wet years. The sample sites were selected with relative uniformity and spatial representativeness of grassland types in the peak growing season. Because of the highest spatial variability within the transitional zone and the lowest spatial variability within the typical steppe zone, a total of 14 sample sites were designed in this study, i.e., 4 sample sites in the desert steppe, 7 sample sites for the transition zone, and 3 sample sites for the typical steppe to obtain vegetation information and soil seed bank sample collection (Figure 1).

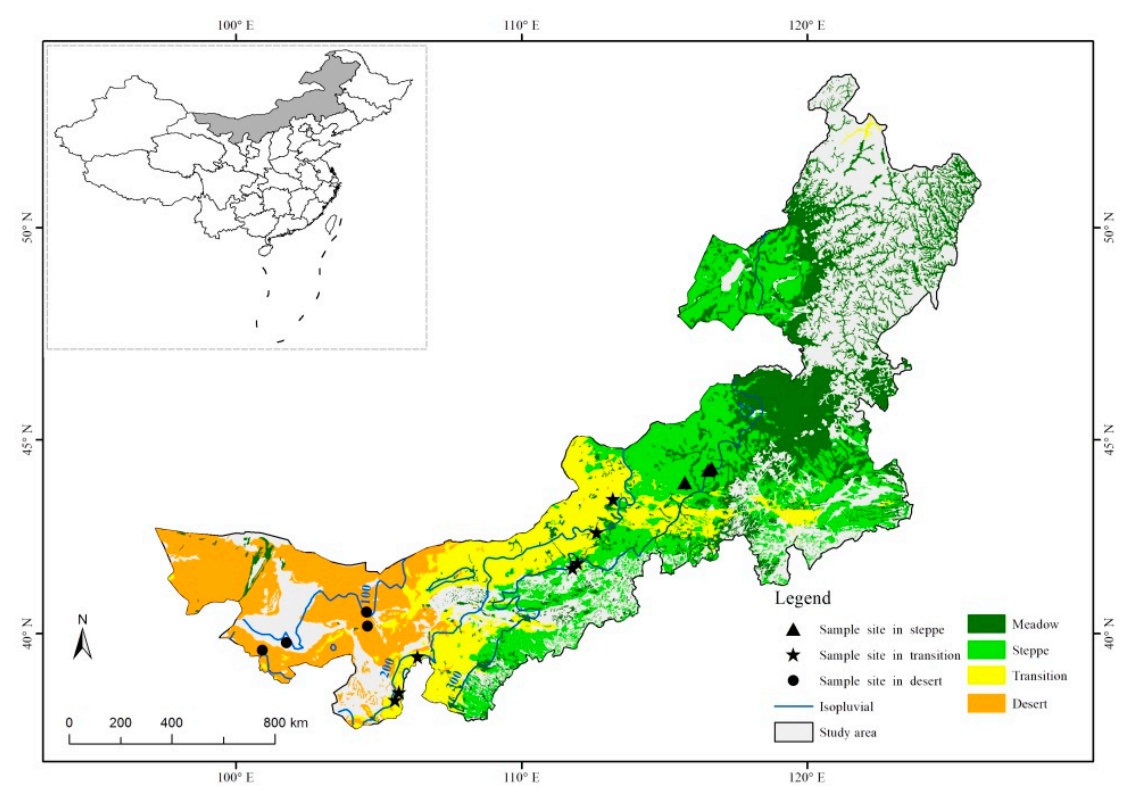

Figure 1. The study area of the desert steppe, transition zone, and typical steppe in Inner Mongolia, China. (Black points represent the sample sites where the vegetation composition was observed and soil seed bank samples were collected.).

The daily precipitation data in 2018 and 2019 were obtained from the nearest meteorological stations. The response of vegetation to precipitation had a certain delay for $50-60$ days $[34,35]$. To measure the vegetation species variations with different precipitation between these two years in the peak growing season (July and August), the mean cumulative precipitation from May to June was gathered and is shown in Table 1.

Table 1. Cumulative average precipitation ( $\mathrm{mm}$ ) from May to June (data from meteorological stations) in desert steppe, transition zone and typical steppe in both 2018 and 2019.

\begin{tabular}{ccccc}
\hline $\begin{array}{c}\text { Grassland } \\
\text { Types }\end{array}$ & $\begin{array}{c}\text { Cumulative Average } \\
\text { Precipitation (mm) from } \\
\text { May to June }\end{array}$ & $\begin{array}{c}\text { Multi-Year Average } \\
\text { Precipitation from } \\
\text { May to June (mm) }\end{array}$ & $\begin{array}{c}\text { Multi-Year Average } \\
\text { Precipitation } \\
\text { ( } \sim \mathbf{m m})\end{array}$ \\
\cline { 2 - 4 } & $\mathbf{2 0 1 8}$ & $\mathbf{2 0 1 9}$ & & \\
\hline Desert steppe & 10.53 & 34.43 & 21.15 & 115 \\
Transition zone & 32.25 & 73.25 & 53.40 & 200 \\
Typical steppe & 42.25 & 73.75 & 76.06 & 300 \\
\hline
\end{tabular}

Note: The data of multi-year average precipitation from May to June $(\sim \mathrm{mm})$ and multi-year average precipitation from 2000-2018 were obtained from https:/ / www.worldclim.org/ (accessed on 20 November 2018).

\subsection{Species Composition Observation by Unmanned Aerial Vehicle (UAV)}

The species composition of vegetation was observed based on a DJI drone (MAVIC Pro, DJI Innovation Company, China; with $3000 \times 4000$ pixels) in the peak growing season, 
from July to August in both 2018 and 2019. This observation time was consistent with the time for the ANPP dataset used in Hu et al. (2018) [13]. For each of the grassland types, BELT flight ways of the FragMAP system were used to take the aerial photos [36]. A BELT flight way consisted of 16 way points, which were evenly distributed within a $40 \times 40 \mathrm{~m}$ plot (Figure 2a). The flight height was set to $2 \mathrm{~m}$, and each photo (covering $2.6 \times 3.5 \mathrm{~m}$ on the ground) was taken vertically at each way point (Figure 2). After automatic flying and aerial photographing, the drone was manually operated to take photos at a height of $0.5 \mathrm{~m}$ randomly in the plot. In each site, three BELT flight ways were set for replication. A total of 41 flight ways (14 sample sites) were set (Figure 1). The species composition was then identified visually and recorded all the species occurring within each aerial photograph $[37,38]$. Species richness is a simple and widely used index that indicates diversity of a study area [39]. In this study, we selected this index to assess the species composition within three grassland types. It was calculated as [40]:
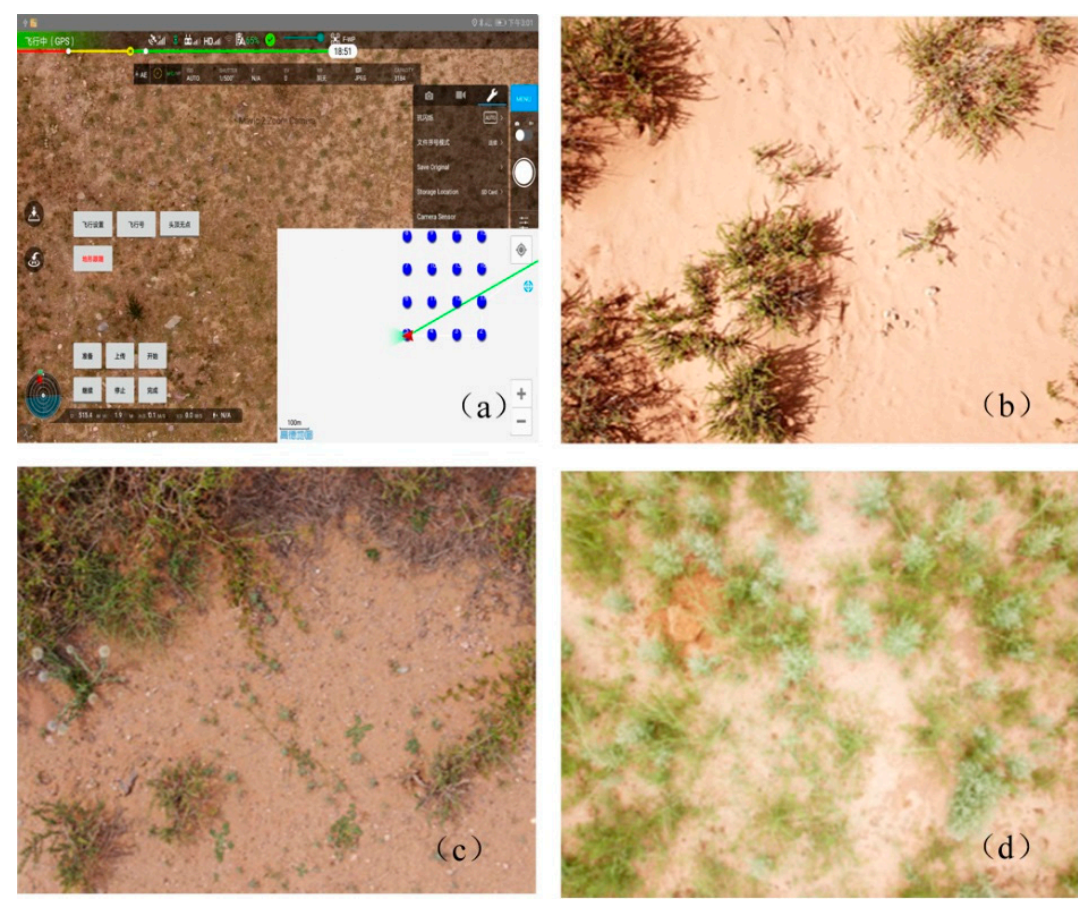

Figure 2. Unmanned aerial vehicle photographing (a); blue points represented the flight way points. Photos obtained from the desert steppe (b), where the predominate plant species is Reaumuria songarica; the transition zone (c), where the predominate plant species are Reaumuria songarica, Astragalus membranaceus and Bassia dasyphylla; and the typical steppe (d), where the predominate plant species are Artemisia scoparia and Stipa capillata in 2019, respectively.

$\mathrm{N}=$ number of species that appeared in each quadrant (mean value from 16 photographs).

Percentage of plant species variation (\%) is used to express the changes in the species composition between the two years. The dry year, 2018, is considered as a reference and the absolute value of the \% change to the wet year, 2019, was calculated.

\subsection{Soil Seed Bank Sampling and Seed Density Test}

The seed bank is characterized by the number of seeds in the soil, and it is changed by the input and output of seeds, being classified by its permanence in the soil as transient or persistent [41,42]. The soil seed bank samples were both collected in April (here identified as the transient soil seed bank) and July or August (as the persistent soil seed bank) [43]. In each sample site, one BELT plot $(40 \times 40 \mathrm{~m})$ where the vegetation species composition was observed by the UAV was selected to collect a soil seed bank sample from. Four corners and central points in the BELT were chosen as a quadrat (Figure 3). Altogether, 5 sets of soil samples were taken from the whole BELT plot. A soil drill with a diameter of $3.5 \mathrm{~cm}$ 
was used to collect soil samples from the upper $(0-5 \mathrm{~cm})$ layers. Ten drilled soil cores of soils were then mixed as a soil sample. A total of 10 soil samples in each plot were collected ( 5 samples each for the transient and persistent soil seed bank, respectively). In total, 140 soil seed bank samples were collected.
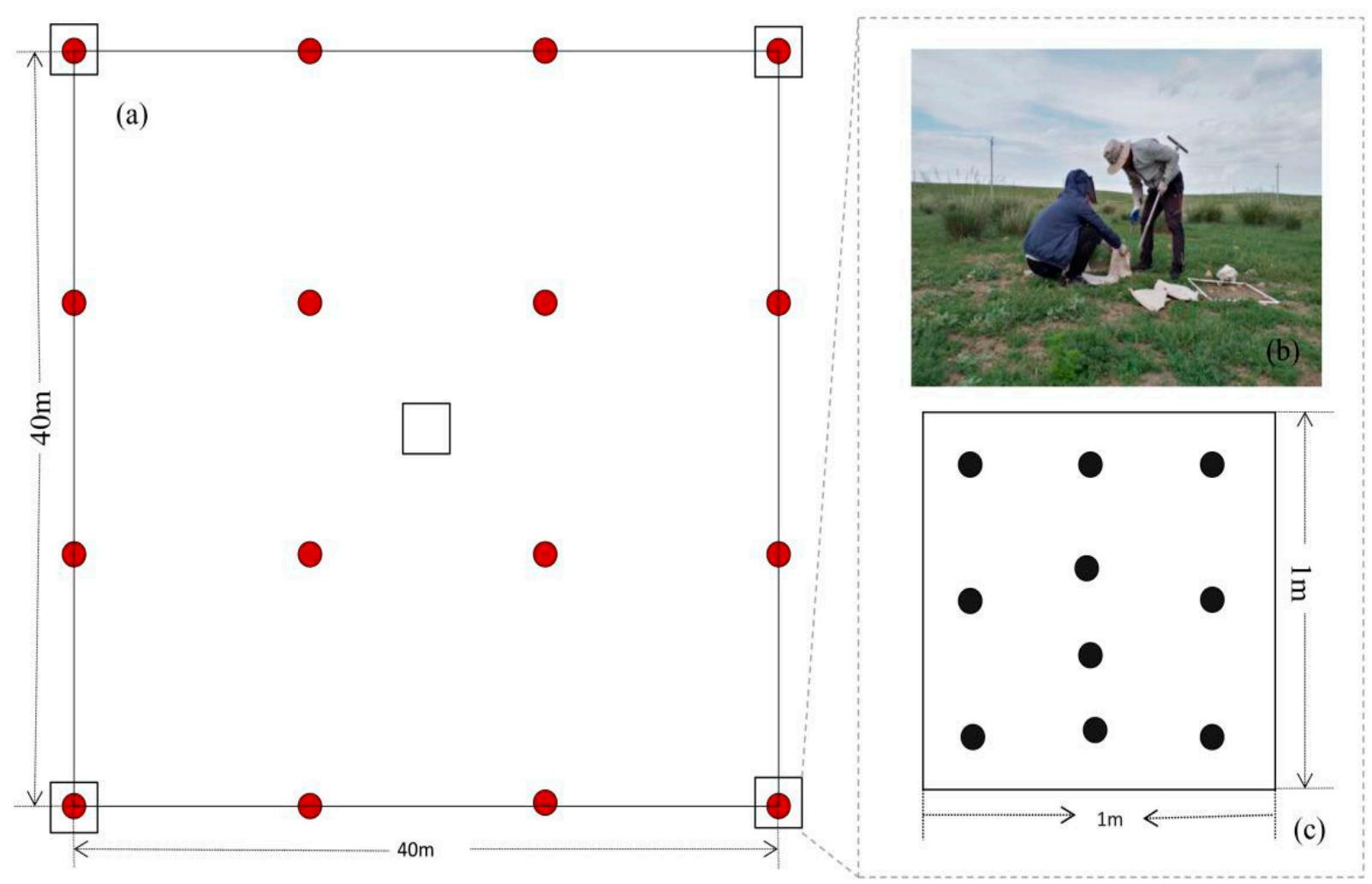

Figure 3. Diagram of soil seed bank sampling within the BELT plot $(40 \mathrm{~m} \times 40 \mathrm{~m})(\mathbf{a})$; soil seed bank samples were collected from five quadrats $(1 \mathrm{~m} \times 1 \mathrm{~m})(\mathbf{b}, \mathbf{c})$. (Red dots denote the way points in the BELT flight way; the small black box represents the position of soil seed bank collection.).

Soil seed bank samples were then dried naturally and taken back to the laboratory for seedling emergence and species identification. Samples were sieved with a $0.3 \mathrm{~mm}$ aperture to remove impurities such as stones and litter. A $30 \times 30 \mathrm{~cm}$ flowerpot was used as a germination bed. A thickness of $10 \mathrm{~cm}$ sterile sand was loaded and soil seed samples were then spread evenly on the surface. The flower pots were then put in an incubator with a temperature of $15 \sim 25^{\circ} \mathrm{C}$, alternating light and darkness $(12 \mathrm{~h} / 12 \mathrm{~h})$. Enough water was added to keep the soil moist. Emerged seedlings were counted daily and identified when characteristics of the seedlings were evident. Whole experiments were considered to be finished when no new seedlings emerged in 7 days. At the end of the experiment, if un-germinated seeds existed, their viability was tested using tetrazolium methods [25]. Finally, the number of species was counted, and the density of soil seed banks (per $\mathrm{m}^{2}$ ) was calculated. In this study, three whole months were taken for seeds to completely germinate.

\subsection{Similarity Index between Soil Seed Bank and Vegetation Species}

The similarity index is an important indicator to evaluate the relationship between soil seed bank and vegetation species [44]. The Sorensen similarity index was used [33,45], which was calculated as follows Equation (1):

$$
\mathrm{SC}=2 \mathrm{~W} /(\mathrm{A}+\mathrm{B})
$$


where A represented the number of species in the soil seed bank, B was the number of species in vegetation and $\mathrm{W}$ was the number of common species both in the soil seed bank and vegetation.

\subsection{Data Analysis}

One-way analysis of variance (ANOVA) was performed to test for differences in plant species richness, percentage of plant species variation, soil seed bank density, and similarity index for three grassland types using SPSS 18.0 software.

\section{Results}

\subsection{Differences in Species Composition Variation among Three Grassland Types}

The floristic composition of the vegetation was clearly identified by aerial photos. In the desert steppe, shrubs mainly dominated the vegetation, including Potaninia mongolica, Reaumuria songarica, Nitraria tangutorum and Sarcozygium xanthoxylon, counting for about $75 \%$ of the total species (Table S1). There were no significant differences in shrub richness between 2018 and 2019 ( $p>0.05$; Figure 4a). The richness of herbaceous species increased in 2019, but was not significantly different from 2018 (Figure 4b). In the transition zone, shrubs' richness showed no significant differences between the two years (Figure 4a). Nevertheless, the richness of herbaceous species significantly $(p<0.05)$ increased in 2019 $(p<0.05 ;$ Figure $4 \mathrm{~b}$ and Table S2). In the typical steppe, species were dominated by herbs, including Artemisia scoparia and Stipa capillata; one shrub species (Caragana microphylla) was observed. The richness of herbaceous species showed no significant differences between 2018 and 2019 ( $p>0.05$; Figure 4 and Table S3).
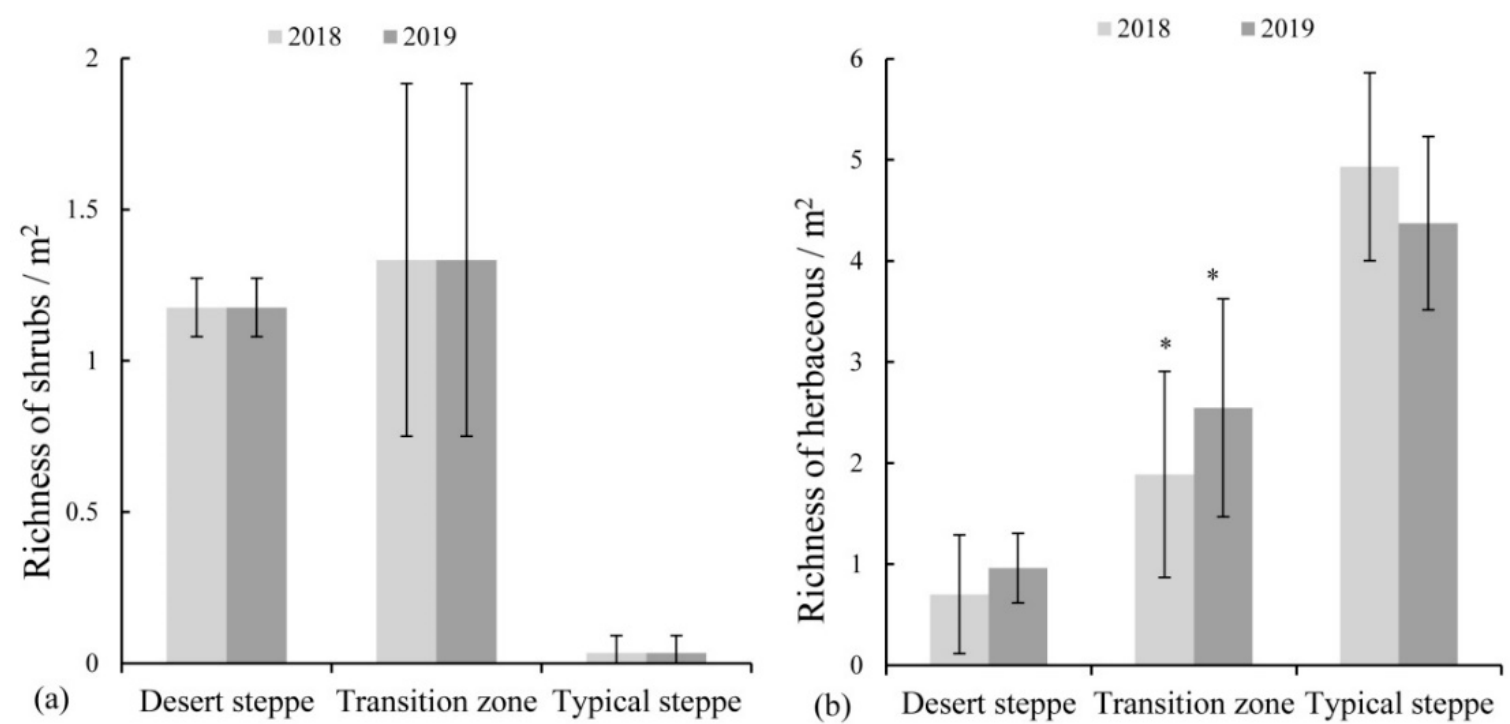

Figure 4. Species richness (species $/ \mathrm{m}^{2}$ ) of shrubs (a) and herbaceous species (b) among three grassland types in 2018 and 2019. (* denotes a significant difference $(p<0.05)$ between two years.).

The variations in species richness between the two years differed among three grassland types; there were $41 \%, 7 \%$ and $13 \%$ variations in species richness in the transition zone, desert steppe and typical steppe, respectively (Figure 5). The variation of the transition zone was the highest $(p<0.05)$, while that in the desert steppe was the lowest. The highest variation in the transition zone was mainly caused by the increased number of herbaceous species (Figure 4). 


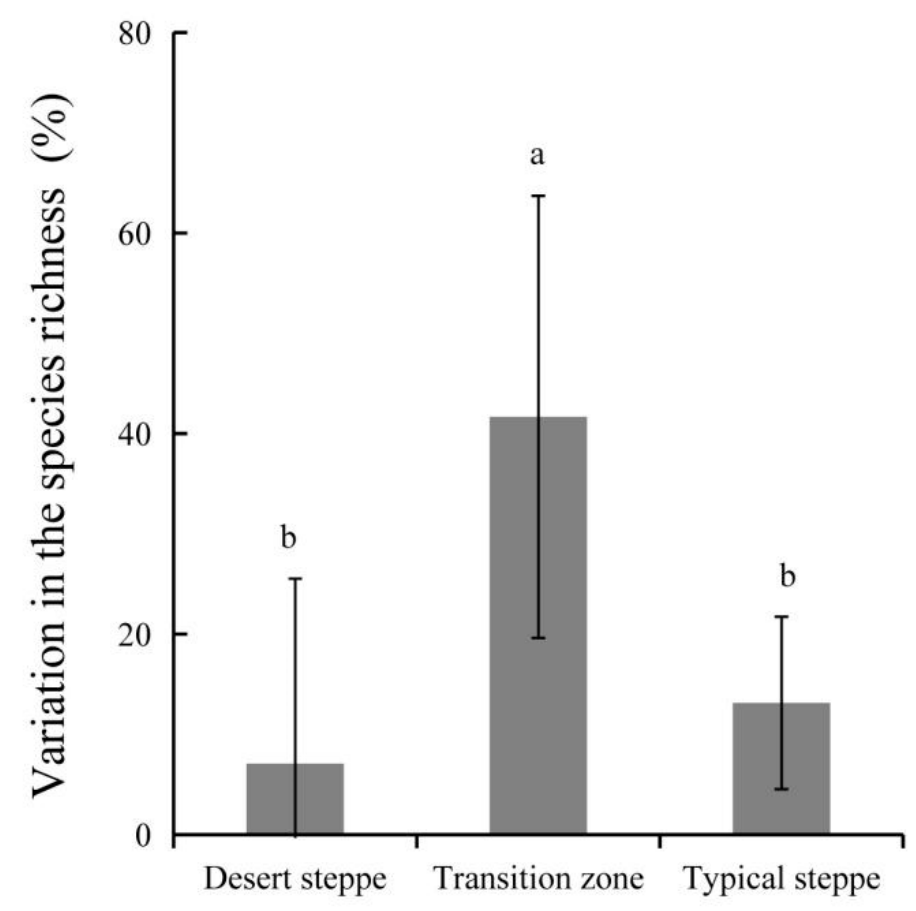

Figure 5. Variation (\%) in the richness of plant species among desert steppe, transition zone and typical steppe. (Different superscripts denote significant difference $(p<0.05)$ in the variations of species among three grassland types of the desert steppe, transition zone and typical steppe.).

\subsection{Soil Seed Bank Density and Species Richness in the Soil Seed Bank}

The transient soil seed bank density was higher than that of the persistent soil seed bank in each grassland type. For the transient soil seed bank, the seed density was the lowest in the desert steppe (62 seeds $\left./ \mathrm{m}^{2}\right)$, while highest in the transition zone $\left(114 \mathrm{seeds} / \mathrm{m}^{2}\right)$ (Figure 6a). All species present in the soil seed bank were identified as herbaceous species. Cleistogenes squarrosa was the most common species observed, and its seed numbers were the highest among the species in all three studied grasslands (Table S4). For the persistent soil seed bank, a similar pattern was observed (Figure 6a). Except for the shrub species of the Compositae family, all plant species were identified as herbaceous. Gramineae were the most common in the transition zone (Table S5).
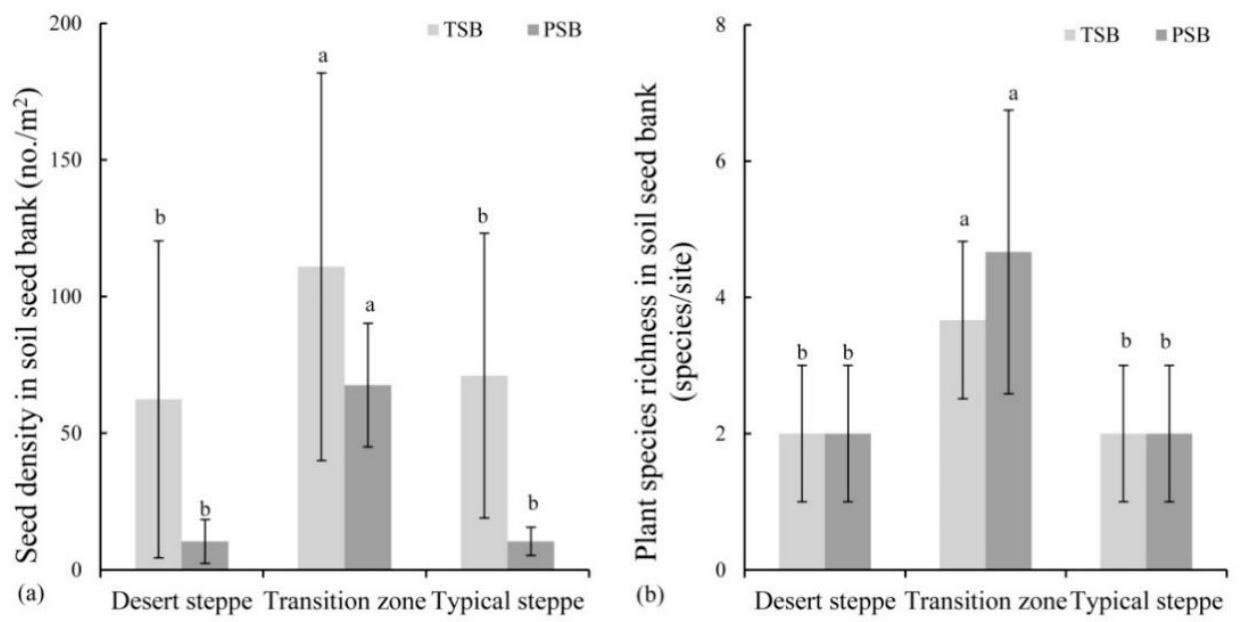

Figure 6. Density (a) and species richness (b) in the transient and persistent soil seed bank in the desert steppe, transition zone and typical steppe. (Different superscripts denote significant differences $(p<0.05)$ among three grassland types of desert steppe, transition zone and typical steppe.). 
For both the transient and persistent soil seed bank, herbaceous species were the dominant ones. Species richness in the soil seed bank in the transition zone (four and five species in the transient and persistent soil seed bank, respectively) was also significantly higher than the other two grassland types $(p<0.05)$ (Figure $6 b)$.

\subsection{Similarity Index between Soil Seed Bank and Vegetation}

The similarity index between the transient soil seed bank and vegetation species composition in 2019 was higher than that in 2018 in all grassland types. The transient soil seed bank in the transition zone showed the highest similarity with the vegetation (38\% and $44 \%$ respectively) in both years (Figure $7 \mathrm{a}$ ), but it was not significant compared to the typical steppe $(p>0.05)$, while the similarity index was lowest in the desert steppe $(p<0.05)$. For the persistent soil seed bank, the similarity was higher in 2019, but not significant $(p>0.05)$ for each of the vegetation types (Figure $7 \mathrm{~b})$. The similarity index in the transition zone was the highest of all grassland types $(p>0.05)$.
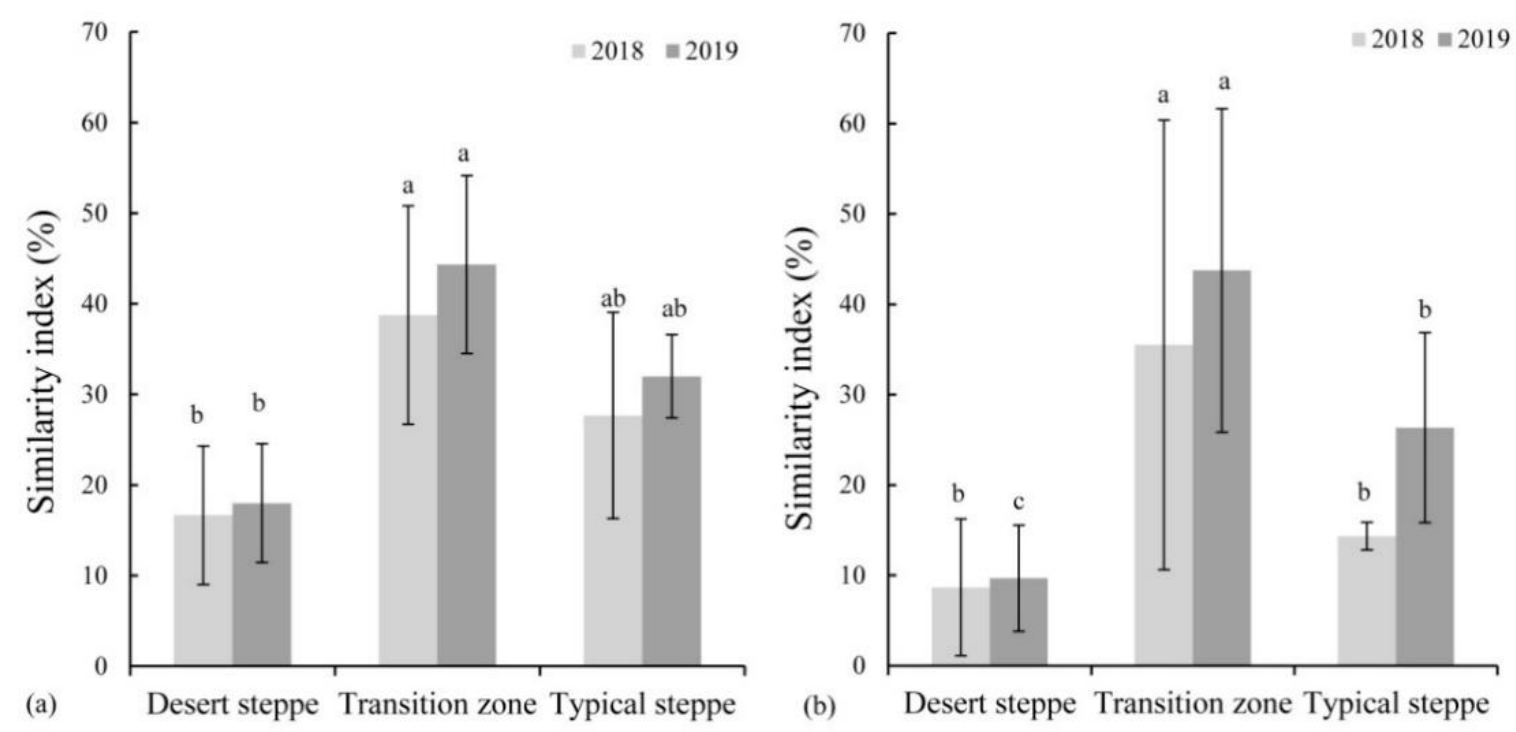

Figure 7. Similarity index (\%) between the transient (a) and persistent (b) soil seed banks and species composition for the years 2018 and 2019 in desert steppe, transition zone and typical steppe. (Different superscripts denote significant differences $(p<0.05)$ among three grassland types of the desert steppe, transition zone and typical steppe.).

\section{Discussion}

\subsection{Highest Seed Density and Similarity Index in the Transition Zone}

This study measured seed density and similarity index in the desert steppe, typical steppe and the transition zone between both. Results showed that the soil seed bank density and similarity index were the highest in the transition zone (Figures 6 and 7). Several factors would explain this pattern: (1) Original plant assemblages [46] were the direct factor. The proportion of annuals and perennials differed in the soil seed bank and the vegetation. These differences possibly resulted in a low similarity between the soil seed bank and the vegetation. It was generally reported that perennials were found to be lacking in the soil seed bank, which meant less common species between the soil seed bank and the vegetation [47]. Thus, the exclusive species in the soil seed bank or vegetation increased the dissimilarity between the soil seed bank and the vegetation [48]. Besides, a different dispersal pattern leads to species differences between the soil seed bank and the vegetation. This was because the seeds were spread by the wind and spread far away from their mother plant. The low soil seed bank density was related to the scarcity of vegetation in the desert steppe [44]. The vegetation in the desert steppe was mostly composed of shrubs (Figure 4 and Table S1); however, we found no shrub seeds in the soil seed bank (Tables S4 and S5), consistent with He [33]. In the typical steppe, the vegetation 
was species-rich and dominated by herbaceous species (Table S3). Although these species produced plenty of seeds, most of them quickly emerged when falling in the soil and only a few seeds remained in the soil. In the transition zone, vegetation was composed of both shrubs and herbaceous species. (2) Abiotic factors such as wind regime, landform and soil condition [41,49-52] also affected soil seed bank density and similarity index. In our study area, the most important abiotic factors controlling both might be the soil moisture content. The water requirement for seed germination was different among species, e.g., for Gramineous (occurred in all study area) ones, the water requirement was low [53], but for species from the family Chenopodiaceae (occurred in the transition zone and typical steppe) (Tables S4 and S5), the requirement was higher [29]. When the precipitation could not meet the seed emergence requirement in the transition zone, seeds would be accumulated in the soil, resulting in a higher seed density. (3) Biotic factors, i.e., seed shape, seed size, the behavior of seed-eating animals, human disturbance, etc., were also main factors affecting soil seed bank density and similarity index [54-59]. Seed size was closely related to seed dispersal, and therefore seed density and similarity index. In the transition zone, the Chenopodiaceae, Compositae, Gramineae, Plantaginaceae, Umbelliferae were found. In contrast, only Compositae and Gramineae were found in the desert steppe and only Chenopodiaceae, Compositae, Gramineae and Liliaceae were found in the typical steppe (Tables S4 and S5). These species produced large quantities of seeds [60] and spread quickly [61,62].

\subsection{Responses of Species to Precipitation and Implications}

Asymmetry was maximized at the transition zone between the desert steppe and typical steppe in Inner Mongolia, China [13]. Hu et al. [13] hypothesized that the new seedlings that emerged from the soil seed bank beneath bare ground strongly influenced the asymmetry $[13,15,16]$. In this study, vegetation species richness was also maximized at the transition zone between dry and wet years (Figure 5). These species are mainly herbaceous species, including Convolvulus ammannii, Erodium stephanianum, Astragalus membranaceus, Artemisia sieversiana and Bassia dasyphylla in the wet year, and Chenopodium glaucum, Artemisia scoparia, Cleistogenes squarrosa and Poa annua in both the dry and wet years (Table S2). Moreover, the number of seedlings were increased dramatically in the wet year (2019). Among these nine species, five species were found in the soil seed bank and were accumulated with high density (Tables S2, S4 and S5). The precipitation is the main limiting factor for plant growth and seedlings emergency in the transition zone $[33,44,63]$. When the precipitation met the requirement for germination [64], large numbers of seedlings emerged. The relatively favorable environment and soil conditions were beneficial to herbaceous species growth $[65,66]$.

In the desert steppe, although six species were found in the soil seed bank (Tables S4 and S5), only Cleistogenes squarrosa observed more seedlings on the vegetation in the wet year (Table S1). Besides, the vegetation species were rare and the similarity index as well as the soil seed bank density were low, thus the productivity will not be changed effectively with the precipitation [14,67]. In the typical steppe, Cirsium japonicum and Convolvulus ammannii were found in 2019. There was no obviously increased number of seedlings in this grassland type (Table S3). Because the vegetation coverage and growth rate were high and there was a linear correlation between productivity and precipitation [67], seeds accumulated in the soil seed bank had less effect on the vegetation.

The soil seed bank would supply most seedlings for vegetation regeneration [19]. The feasibility of vegetation restoration using the soil seed bank is largely dependent on its seed density and species composition $[19,23]$. Therefore, the increased number of vegetation species and similarity in the transition zone in a wet year implied that seeds accumulated in the soil seed bank might contribute to the asymmetry. However, long-term repeated monitoring of vegetation species with different precipitation regimes is required to test the asymmetry hypothesis. 


\subsection{UAV Application for the Mechanism Study of ANPP Asymmetric Response to Precipitation}

Our study demonstrated that the soil seed bank potentially contributed to the asymmetry in the transition zone. The asymmetry was calculated based on ANPP data derived from the normalized difference vegetation index (NDVI) [13]. At present, the NDVI was one of the most widely used indices in grassland ANPP estimation [13,68,69]. Therefore, to test the hypothesis [13] of whether new seedlings or the growth of the existing plants contribute to the asymmetry, the dynamic changes in vegetation species and their NDVI should be monitored.

Traditional monitoring methods of the dynamic changes in the vegetation composition were usually limited by time, labor and resources [70]. The UAV method in this study, when appropriately calibrated, may overcome these limitations. Previous studies also demonstrated that the diversity indices derived from UAV photos are comparable with those from traditional methods [37,38,71]. For each set of way points, multiple flights with a fixed height $(2 \mathrm{~m})$ could be executed at different times to conduct repeated monitoring [36]. In this way, long-term monitoring over large regions can be realized. In addition to traditional cameras, multispectral cameras mounted on UAVs have become popular recently, which can be applied to monitor NDVIs with high spatial resolution [72]. We have performed preliminary experiments to take repeated photos over fixed locations using a UAV with a multispectral camera. These photos include five bands, and the NDVI of the regional shrubs and herbaceous species can be estimated in the ArcMap software. The proportions (\%) of shrubs/herbaceous NDVI changes to the regional NDVI changes were then calculated. The preliminary results showed that the NDVI increased $20 \%$ under wet conditions in the transition zone. Although woody species contribute a large amount to the NDVI, their contribution to the NDVI changes with the precipitation is low (by $10 \%$ ), while herbaceous species contribute $90 \%$. In our future studies, we will monitor changes in species and their NDVI over large regions, including the desert steppe, typical steppe and the transition zone, to test the hypothesis of the asymmetric response of ANPP to precipitation using a UAV with a multispectral camera.

\section{Conclusions}

This study investigated the seed density and similarity index between vegetation and species in the soil seed bank in the desert steppe, typical steppe and transition zone. The results showed that both the seed density and similarity index reached the highest values in the transition zone, where the asymmetry was maximized. These results implied that new seedlings that emerged from the soil seed bank beneath bare ground might be the most important reason for the asymmetry. However, the dynamic changes in species and their NDVI should be monitored to test whether new seedlings or the existing plants contribute to the asymmetry most. A UAV mounted with a multispectral camera can be a feasible tool. The results would be helpful for vegetation restoration and desertification control in semi-arid regions of Northern China, as well as similar regions all over the world.

Supplementary Materials: The following are available online at https:/ / www.mdpi.com/article / 10.3390/plants10091890/s1. Table S1: Vegetation species obtained by UAV in the desert steppe. Table S2: Vegetation species obtained by UAV in the transition zone. Table S3: Vegetation species obtained by UAV in the typical steppe. Table S4: Species identified in the transient soil seed bank for the desert steppe, transition zone and typical steppe. Table S5: Species identified in the persistent soil seed bank for the desert steppe, transition zone and typical steppe.

Author Contributions: All authors contributed significantly to this manuscript. Y.L., B.M. and S.Y. designed this study, written and revised the manuscript. M.S., H.Z., Y.S., J.Z., L.C., J.L. for the field observation and laboratory experiment test, data analysis and revise of the manuscript. All authors have read and agreed to the published version of the manuscript. 
Funding: This study was supported by the Planned Science-Technology Project of Inner Mongolia, China (2021GG0050), the National Key R\&D Program of China (2017YFA0604801), the National Nature Science Foundation of China (41801102), and the Basic Scientific Research Foundation Special Project of the China Institute of Water Resources and Hydropower Research (nos. MK2020J08).

Institutional Review Board Statement: Not applicable.

Informed Consent Statement: Not applicable.

Data Availability Statement: The data of multi-year average precipitation from May to June ( $\sim \mathrm{mm})$ and multi-year average precipitation from 2000-2018 were obtained from https:/ / www.worldclim. org/ (accessed on 20 November 2018).

Acknowledgments: We thank Bo Xiang for providing information on precipitation, and Xiameng $\mathrm{Lu}$ and Yuting Huang for help with the experiments. We also thank the Naiman Desertification Research Station, Cold and Arid Regions Environmental and Engineering Research Institute, Chinese Academy of Sciences for providing the field observation.

Conflicts of Interest: The authors declare no conflict of interest.

\section{References}

1. Gidey, E.; Dikinya, O.; Sebego, R.; Segosebe, E.; Zenebe, A. Predictions of future meteorological drought hazard ( 2070) under the representative concentration path (RCP) 4.5 climate change scenarios in Raya, Northern Ethiopia. Modeling Earth Syst. Environ. 2018, 4, 475-488. [CrossRef]

2. Cleland, E.E.; Goodale, U.M. Co-limitation by nitrogen and water constrains allocation response to drought in deciduous and evergreen shrubs in a semi-arid ecosystem. Plant Ecol. 2019, 220, 213-225. [CrossRef]

3. Carlsson, M.; Merten, M.; Kayser, M.; Isselstein, J.; Wrage-Mönnig, N. Drought stress resistance and resilience of permanent grasslands are shaped by functional group composition and N fertilization. Agric. Ecosyst. Environ. 2017, 236, 52-60. [CrossRef]

4. Ochoa-Hueso, R.; Collins, S.L.; Delgado-Baquerizo, M.; Hamonts Kelly Pockman, W.T.; Sinsabaugh, R.L.; Smith, M.D.; Knapp, A.K.; Power, S.A. Drought consistently alters the composition of soil fungal and bacterial communities in grasslands from two continents. Glob. Chang. Biol. 2018, 24, 2818-2827. [CrossRef] [PubMed]

5. Stampfli, A.; Bloor, J.M.G.; Fischer, M.; Zeiter, M. High land-use intensity exacerbates shifts in grassland vegetation composition after severe experimental drought. Glob. Chang. Biol. 2018, 24, 2021-2034. [CrossRef]

6. deMenocal, P.; Guilderson, T.; Adkins, J.; Sarnthein, M.; Baker, L.; Yarusinsky, M.; Ortiz, J. Abrupt onset and termination of the African Humid Period: Rapid climate responses to gradual insolation forcing. Quat. Sci. Rev. 2000, 19, 347-361. [CrossRef]

7. Rietkerk, M.; Dekker, S.C.; de Ruiter, P.C.; van de Koppel, J. Self-organized patchiness and catastrophic shifts in ecosystems. Science 2004, 305, 1926-1929. [CrossRef] [PubMed]

8. Kéfi, S.; Rietkerk, M.; Alados, C.L.; Pueyo, Y.; Papanastasis, V.P.; ElAich, A.; De Ruiter, P.C. Spatial vegetation patterns and imminent desertification in Mediterranean arid ecosystems. Nature 2007, 449, U213-U215. [CrossRef]

9. Knapp, A.K.; Ciais, P.; Smith, M.D. Reconciling inconsistencies in precipitation-productivity relationships: Implications for climate change. New Phytol. 2017, 214, 41-47. [CrossRef]

10. Luo, Y.; Jiang, L.; Niu, S.; Zhou, X. Nonlinear responses of land ecosystems to variation in precipitation. New Phytol. 2017, $214,5$. [CrossRef]

11. Zhang, L.; Wang, J.; Zhao, R.; Guo, Y.; Hao, L. Aboveground net primary productivity and soil respiration display different responses to precipitation changes in desert grassland. J. Plant Ecol. 2021, rtab067. [CrossRef]

12. Deng, Q.; Aras, S.; Yu, C.L.; Dzantor, E.K.; Fay, P.A.; Luo, Y. Effects of precipitation changes on aboveground net primary production and soil respiration in a switchgrass field. Agric. Ecosyst. Environ. 2017, 248, 29-37. [CrossRef]

13. Hu, Z.M.; Guo, Q.; Li, S.G.; Piao, S.L.; Knapp, A.; Philippe, C.; Li, X.; Yu, G.; Johannes, K. Shifts in the dynamics of productivity signal ecosystem state transitions at the biome-scale. Ecol. Lett. 2018, 21, 1457-1466. [CrossRef]

14. Knapp, A.K.; Smith, M.D. Variation among biomes in temporal dynamics of aboveground primary production. Science 2001, 291, 481-484. [CrossRef] [PubMed]

15. Holm, A.M.; Watson, I.W.; Loneragan, W.A.; Adams, M.A. Loss of patch-scale heterogeneity on primary productivity and rainfalluse efficiency in Western Australia. Basic Appl. Ecol. 2003, 4, 569-578. [CrossRef]

16. Li, X.J.; Li, X.R.; Song, W.M.; Gao, Y.P.; Zheng, J.G.; Jia, R.L. Effects of crust and shrubs patches on runoff, sedimentation, and related nutrient $(\mathrm{C}, \mathrm{N})$ redistribution in the desertified steppe zone of the Tengger Desert, Northern China. Geomorphology 2008, 96, 221-232. [CrossRef]

17. Walck, J.L.; Baskin, J.M.; Baskin, C.C.; Hidayati, S.N. Defining transient and persistent seed banks in species with pronounced seasonal dormancy and germination patterns. Seed Sci. Res. 2005, 15, 189-196. [CrossRef]

18. Fisher, J.L.; Loneragan, W.A.; Dixon, K.; Veneklaas, E.J. Soil seed bank compositional change constrains biodiversity in an invaded species-rich woodland. Biol. Conserv. 2009, 142, 256-269. [CrossRef] 
19. Jalili, A.; Hamzeh'ee, B.; Asri, Y.; Shirvany, A.; Yazdani, S.; Khoshnevis, M.; Zarrinkamar, F.; Ghahramani, M.-A.; Safavi, R.; Shaw, S. Soil seed banks in the arasbaran protected area of Iran and their significance for conservation management. Biol. Conserv. 2003, 109, 425-431. [CrossRef]

20. Yan, J.C.; Liang, C.Z.; Fu, X.Y.; Wang, W.; Wang, L.X.; Jia, C.Z. The response of annual plant traits to rainfall variation in steppe and desert regions. Acta Prataculturae Sin. 2013, 22, 68-76.

21. Wang, W.; Ma, K.P.; Gao, X.M. Relationship between soil seed bank and vegetation. In Proceedings of the 2nd National Symposium on Biodiversity Conservation and Sustainable Use, Beijing, China, 4 November 1996; pp. $288-292$.

22. Duncan, R.P.; Diez, J.M.; Sullivan, J.J.; Wangen, S.; Miller, A.L. Safe sites, seed supply, and the recruitment function in plant populations. Ecology 2009, 90, 2129-2138. [CrossRef] [PubMed]

23. Feldman, S.R.; Alzugaray, C.; Lewis, J.P. Relationship between the soil seed bank and vegetation of tall grassland of Spartina argentinensis. Investig. Agrar. 2007, 34, 41-48. [CrossRef]

24. Yan, Q.L.; Liu, Z.M.; Zhen, J.J.; Luo, Y.; Wang, H.; Jiang, D. Structure, pattern and mechanisms of formation of seed banks in sand dune systems in northeastern Inner Mongolia, China. Plant Soil 2005, 277, 175-184.

25. Yang, L.; Wang, Y.R.; Yu, J.D. Review of research on seed bank of desert regions. Acta Pratacult. Sin. 2010, 2, $227-234$.

26. Huang, X.Y.; Wang, K.; Wang, Y.T.; Kan, Y.C.; Zhang, Y.J.; Shao, X.Q. Soil seed bank dynamics during natural restoration by fence in a typical steppe of Inner Mongolia. Acta Agrestia Sin. 2011, 19, 38-42.

27. Wang, Y.C.; Mark, K.J.; Ren, G.H. Species shifts in above-ground vegetation and the soil seed bank in the inter-dune lowlands of an active dune field in Inner Mongolia, China. Basic Appl. Ecol. 2015, 16, 490-499. [CrossRef]

28. Qian, J.; Liu, Z.; Hatier, J.H.B.; Liu, B. The vertical distribution of soil seed bank and its restoration implication in an active sand dune of northeastern Inner Mongolia, China. Land Degrad. Dev. 2016, 27, 305-315. [CrossRef]

29. Wang, Y.C.; Chu, L.; Daryanto, S.; Lü, L.Y.; Ala, M.S.; Wang, L.X. Sand dune stabilization changes the vegetation characteristics and soil seed bank and their correlations with environmental factors. Sci. Total Environ. 2018, 648, 500-507. [CrossRef]

30. Kang, S.; Ma, W.; Li, F.Y.; Zhang, Q.; Niu, J.; Ding, Y.; Han, F.; Sun, X. Functional redundancy instead of species redundancy determines community stability in a typical steppe of Inner Mongolia. PLoS ONE 2015, 10, e0145605. [CrossRef]

31. Liu, G.; Xie, X.; Ye, D.; Ye, X.; Tuvshintogtokh, I.; Mandakh, B.; Huang, Z.; Dong, M. Plant functional diversity and species diversity in the Mongolian steppe. PLoS ONE 2013, 8, e77565.

32. DAHV (Department of Animal Husbandry and Veterinary, Ministry of Agriculture); GSAHV (General Station of Animal Husbandry and Veterinary, Ministry of Agriculture). Rangeland and Resources of China; China Science and Technology Press: Beijing, China, 1996. (In Chinese)

33. He, M.Z. Environmental effects on distribution and composition of desert vegetations in Alxa Plateau: IV. Soil seed banks. J. Desert Res. 2010, 30, 287-295.

34. Cui, L.; Yang, S.J.; Fan, Y.W. Ten-day response of vegetation NDVI to the variations of temperature and precipitation in Eastern China. Acta Geogr. Sin. 2009, 64, 850-860.

35. Liu, C.L.; Pan, R.H.; Wu, J.J.; Yan, F. Temporal lag of grassland vegetation growth response to precipitation in Xilinguolemeng. Arid. Land Geogr. 2009, 32, 512-518.

36. Yi, S. FragMAP: A tool for long-term and cooperative monitoring and analysis of small-scale habitat fragmentation using an unmanned aerial vehicle. Int. J. Remote Sens. 2017, 38, 2686-2697. [CrossRef]

37. Sun, Y.; Yi, S.H.; Hou, F.J. Unmanned aerial vehicle methods makes species composition monitoring easier in grassland. Ecol. Indic. 2018, 95, 825-830. [CrossRef]

38. Qin, Y.; Yi, S.; Ding, Y.; Wang, Z. Effects of plateau pikas' foraging and burrowing activities on vegetation biomass and soil organic carbon of alpine grasslands. Plant Soil 2020, 458, 201-216. [CrossRef]

39. Karen, R.H.; Hartnett, D.C.; Robert, C.C.; Owensby, C.E. Grazing management effects on plant species diversity in tallgrass prairie. J. Range Manag. 2004, 57, 58-65.

40. Bonham, C.D. Measurements for Terrestrial Vegetation, 2nd ed.; John Wiley and Sons: Chichester, UK, 2013.

41. Thompson, K.; Grime, J.P. Seasonal variation in the seed bank of herbaceous species in ten contrasting habitats. J. Ecol. 1979, 67, 893-921. [CrossRef]

42. Baskin, C.C.; Baskin, J.M. Seeds: Ecology, Biogeography, and Evolution of Dormancy and Germination; Academic Press: Cambridge, MA, USA, 1998.

43. Bai, W.J.; Jiao, J.Y. A review of soil seed bank. Agric. Res. Arid. Areas 2006, 6, 195-203.

44. Zeng, Y.J.; Wang, Y.R.; Nan, Z.B.; Dong, W.; Li, B. Soil seed bank of different grassland types of Alashan arid desert region, Inner Mongolia. Chin. J. Appl. Ecol. 2003, 14, 1457-1463.

45. Magurran, A. Diversity indices and species abundance models. In Ecological Diversity and Its Measurement; Princeton University Press: Princeton, UK, 1988; pp. 8-45.

46. Grime, J.P. Plant Strategies, Vegetation Processes, and Ecosystem Properties; John Willey and Sons: Hoboken, NJ, USA, 2001.

47. Navarra, J.J.; Quintana-Ascencio, P.F. Spatial pattern and composition of the Florida scrub seed bank and vegetation along an anthropogenic disturbance gradient. Appl. Veg. Sci. 2012, 15, 349-358. [CrossRef]

48. Amiaud, B.; Touzard, B. The relationships between soil seed bank, aboveground vegetation and disturbances in old embanked marshlands of western France. Flora 2004, 199, 25-35. [CrossRef] 
49. Chambers, J.C.; MacMahon, J.A. A day in the life of a seed: Movements and fates of seeds and their implications for natural and managed systems. Ann. Rev. Ecol. Syst. 1994, 25, 263-292. [CrossRef]

50. Chambers, J.C.; MacMahon, J.A.; Haefner, J.H. Seed entrapment in alpine ecosystems: Effects of soil particle size and diaspore morphology. Ecology 1991, 72, 1668-1677. [CrossRef]

51. Okubo, A.; Levin, S.A. A theoretical framework for data analysis of wind dispersal of seeds and pollen. Ecology 1989, 70, 329-338. [CrossRef]

52. Reichman, J. Spatial and temporal variation of seed distributions in Sonoran desert soils. J. Biogeogr. 1984, 11, 1-11. [CrossRef]

53. Guo, J.L.; Li, Q.F.; Zhang, S.Y.; Tian, S.X. Study on seedling vigour and drought tolerance of Three Rhizomatose grasses. J. Arid. Land Resour. Environ. 2008, 22, 171-174.

54. Guo, Q.; Brown, J.H.; Valone, T.J. Constrains of seed size on plant distributions and abundance. Ecology 2000, 81, 2149-2155. [CrossRef]

55. Liddle, M.J.; Parlange, J.L.; Bulow-Olsen, A. A simple method for measuring diffusion rates and predation of seed on the soil surface. J. Ecol. 1987, 75, 1-8. [CrossRef]

56. Moles, A.T.; Hodson, D.W.; Webb, C.J. Seed size and shape and persistence in the soil in the New Zealand flora. Oikos 2000, 89, 541-545. [CrossRef]

57. O'Connor, T.G.; Pickett, G.A. The influence of grazing on seed production and seed bank of some African savanna grassland. J. Appl. Ecol. 1992, 29, 247-260. [CrossRef]

58. Thompson, K.; Band, S.R.; Hodgson, J.G. Seed size and shape predict persistence in soil. Funct. Ecol. 1993, 7, 236-241. [CrossRef]

59. Li, C.; Bo, X.; Wang, Q.; Zheng, R.; Wu, J. Responses of soil seed bank and vegetation to the increasing intensity of human disturbance in a semi-arid region of northern China. Sustainability 2017, 9, 1837. [CrossRef]

60. Plassmann, K.; Brown, N.; Edwards-Jones, J.G. Can soil seed bank contribute to the restoration of dune-slacks under conservation management? Appl. Veg. Sci. 2009, 12, 199-210. [CrossRef]

61. Bossuyt, B.; Hermy, M. Seed bank assembly follows vegetation succession in dune slacks. J. Veg. Sci. 2004, 15, 449-456. [CrossRef]

62. Thompson, K. Seeds and seed bank. New Phytol. 1987, 106, 23-34. [CrossRef]

63. Noy-Meir, I. Desert ecosystems: Environment and producers. Ann. Rev. Ecol. Syst. 1973, 4, 23-51. [CrossRef]

64. Brown, G. Species richness, diversity and biomass production of desert steppe annuals in an Ungrazed Rhanterium epapposum community over three growth seasons in Kuwait. Plant Ecol. 2003, 165, 53-68. [CrossRef]

65. Stark, K.E.; Lundholm, J.T.; Larson, D.W. Relation-ships between seed bank and spatial heterogeneity of North American alvar vegetation. J. Veg. Sci. 2003, 14, 205-212. [CrossRef]

66. Ye, X.; Li, L.; Baskin, C.C.; Baskin, J.M.; Du, J.; Huang, Z. Sand burial helps regulate timing of seed germination of a dominant herb in an inland dune ecosystem with a semiarid temperate climate. Sci. Total Environ. 2019, 680, 44-50. [CrossRef]

67. Bai, Y.; Wu, J.; Xing, Q.; Pan, Q.; Huang, J.; Yang, D.; Han, X. Primary production and rain use efficiency across a precipitation gradient on the Mongolia plateau. Ecology 2008, 89, 2140-2153. [CrossRef]

68. Yang, Y.; Fang, J.; Ma, W.; Guo, D.; Mohammat, A. Largescale pattern of biomass partitioning across China's grasslands. Glob. Ecol. Biogeogr. 2010, 19, 268-277. [CrossRef]

69. Zhongmin, H.; Guirui, Y.; Jiangwen, F.; Huaping, Z.; Shaoqiang, W.; Shenggong, L. Precipitation-use efficiency along a 4500-km grassland transect. Glob. Ecol. Biogeogr. 2010, 19, 842-851. [CrossRef]

70. Arif, M.S.M.; Gülch, E.; Tuhtan, J.A.; Thumser, P.; Haas, C. An investigation of image processing techniques for substrate classification based on dominant grain size using RGB images from UAV. Int. J. Remote Sens. 2016, 38, 2639-2661. [CrossRef]

71. Wei, T.; Shangguan, D.; Yi, S.; Ding, Y. Characteristics and controls of vegetation and diversity changes monitored with an unmanned aerial vehicle (UAV) in the foreland of the Urumqi Glacier No. 1, Tianshan, China. Sci. Total Environ. 2020, 771, 145433. [CrossRef] [PubMed]

72. Mikhailova, M.P.; Sinegovskaia, V.T.; Boiarskii, B.S.; Sinegovskii, M.O.; Boiarskaia, A.I. Evaluation of the influence of biologically active substances on the physiological processes of soybean plants with the use of multispectral camera and unmanned aerial vehicle. IOP Conf. Ser. Earth Environ. Sci. 2020, 548, 032028. [CrossRef] 